Misha Becker

Institute for Research in Cognitive Science

mkbecker@linc.cis.upenn.edu

\title{
The Syntactic Structure of Predicatives: Clues from the Omission of the Copula in Child English
}

\begin{abstract}
This paper explores the syntax of main clause predicatives from the perspective of trying to account for an asymmetry in copular constructions in certain languages. One of the languages in which we find such an asymmetry is child English (around age 2). Specifically, new results show that children acquiring English tend to use an overt (and inflected) copula in individual-level predicatives, but they tend to omit the copula in stage-level predicatives. The analysis adopted to account for this pattern draws on evidence from adult English, Russian, Spanish and Portuguese that stage-level predicates are Aspectual (they contain AspP) while individual-level predicates are not (they involve only a lexical Small Clause predicate). Children's omission of the copula in structures with AspP is linked to the fact that at this stage of development, children fail to require finiteness in main clauses. In particular, $\mathrm{Asp}^{0}$ is temporally anchored in child English, thereby obviating the need for a finite (temporally anchored) Infl, i.e. an inflected copula.
\end{abstract}

\section{Introduction}

Predicative expressions, which consist of a subject, a copula and a nominal, adjectival or locative (PP) predicate, can be categorized as stage-level or individual-level.

(1) Rodney is in the kitchen/tired. (stage-level)

(2) Rodney is a cat/fat. (individual-level)

This semantic contrast is well known. It is characterized by Carlson (1977) in terms of a difference in the sort of thing the predicate applies to. An individual-level predicate applies directly to an INDIVIDUAL (e.g. an object or a person), denoted by the subject. A stage-level predicate applies to a STAGE of the subject (i.e. (1) means that the predicate [in the kitchen] or [tired] applies to a stage of Rodney, not to Rodney himself.) A stage is defined as a spatio-temporal slice of an individual.

One approach to capturing this contrast is to say that the predicate in a sentence like (2) denotes a "permanent" property, while the predicate in a sentence like (1) denotes a "temporary" property. While this sort of generalization is true in many cases, it is not quite accurate and gives the false impression that we might be able to tell (1)- and (2)-type predicates apart based on the length of time the property holds. Instead, the argument made here is that the semantic difference between stage- and individual-level predicates should be analyzed as a difference of grammatical Aspect. Grammatical Aspect encodes information about the imperfectivity or perfectivity of an event or eventuality, and this information is encoded syntactically (i.e. by the projection of an Aspect 
Phrase, the head of which contains features for (im)perfectivity). ${ }^{1}$ More generally, Aspect asserts an eventuality of the predicate (e.g. in (1) it is asserted that an eventuality of Rodney's being in the kitchen or being tired is taking place). Since eventualities can be situated in time, predicates with Aspect can be said to be temporal in nature, as opposed to being atemporal. In clauses that lack Aspect no eventuality of the predicate is asserted; predicates in such clauses are atemporal.

The relationship between Aspect and the stage/individual distinction is that stage-level predicates project AspP (they are TEMPORAL) but individual-level predicates do not (they are ATEMPORAL). ${ }^{2}$ Support for this position is provided from English perception verb constructions and from main clause predicatives in Spanish, Portuguese and Russian.

In addition to the proposal for a syntactic/aspectual analysis of the stage-/individual-level distinction, an independent proposal is made for the temporal anchoring of main clauses: main clauses must be temporally anchored to the discourse in order to receive temporal reference. The manner in which clauses are anchored is made explicit in section 5 . The main contribution of this paper is that the proposal for a syntactic asymmetry between stage- and individual-level predicatives, coupled with the analysis of the temporal anchoring of main clauses, allows us to account for the pattern of omission of the copula in main clause predicatives in child English.

The rest of the paper is structured as follows. Section 2 goes through the basic semantic and syntactic distinctions between stage- and individual-level predicates, and some traditional accounts of the distinction are summarized. The syntactic distinctions in particular point to a difference of Aspect between the two types of predicatives (as mentioned above: stage-level predicates are argued to be aspectual, while individual-level predicates are non-aspectual). The following section provides further support for this view from adult non-English languages. Syntactic alternations in main clause predicatives in Russian (involving the case of the predicate), and Spanish and Portuguese (involving the form of the copula) suggest an alternation based on Aspect. In addition to adult grammars, we find an alternation in copular constructions in new data presented from child standard English. Here the alternation is in the overtness of the copula. The data show that children omit the copula in stage-level predicatives (clauses with Aspect) but tend to produce an overt copula in individual-level predicative clauses (those without Aspect).

In section 5, an account is given of the correlation between the presence of AspP in a clause and a null copula, and the absence of AspP and an overt copula in child English. The account is based on a requirement for temporal anchoring in main clause predicatives. In the final section, this account is shown to be extendable to cover the pattern of copula omission in adult Hebrew.

\section{A Syntactic Asymmetry}

At first blush, the sentences in (1) and (2) above appear to have the same structure, modulo the different lexical categories of the predicates. We might adopt, as a point of departure, the basic structure in (3), following Stowell (1981). ${ }^{3}$

\footnotetext{
'I understand 'perfective' aspect to indicate a completed situation, or to refer to a situation in its entirety, while 'imperfective' aspect is understood to indicate an uncompleted situation, or to refer to the "internal temporal structure of a situation" (Comrie, 1976, p. 24). Henceforth I use the term 'Aspect' to refer only to grammatical, not lexical, Aspect.

${ }^{2}$ It is worth noting that Carlson also conceived of the stage/individual contrast as one involving a contrast in temporality. Carlson (1979) writes of the "basically atemporal nature of individuals as opposed to their time-bound stages." (Carlson, 1979, p. 57).

${ }^{3}$ That no VP is projected in this structure is due to the fact that I believe the inflected copula is simply the spell-out of finiteness features in Infl, rather than a raised verb. Arguments for this view are given in Becker (to appear).
} 
(3)

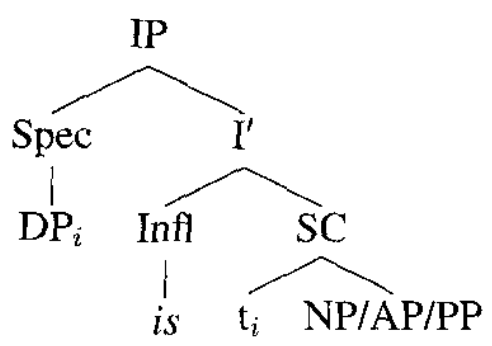

However, there are a number of environments that distinguish stage- from individual-level predicates and thereby give us reason to think they might differ structurally. I will briefly go through the main diagnostics here.

One difference between stage- and individual-level predicates is that only stage-level predicates can be modified by a spatial or temporal modifier, as shown in (4a-b).

(4) a. Rodney is in the kitchen all the time.

b. ?? Rodney is a cat all the time.

(While certainly true, it is semantically odd to say that Rodney is a cat all the time; it seems to imply that there might be times at which he's not a cat, which is not possible in our world. ${ }^{4}$ )

In addition to modification by a temporal modifier, the ability to occur in a when-clause is a property of stage- but not individual-level predicates. This is shown in (5).

(5) a, When Rodney is in the kitchen, he eats my parsley.

b. ?? When Rodney is a cat, he eats my parsley.

According to Kratzer (1995), the reason (5b) is semantically ill-formed is that it lacks a semantic Event variable (Davidson, 1967): she argues that a when-clause contains an implicit ALWAYS operator that looks for a variable to bind in the restrictor clause. This need is satisfied in the structure in (6a), corresponding to (5a), but not in (6b), which corresponds to (5b).

(6) a. ALWAYS 1 [in-kitchen(Rodney, I)][eat(Rodney, my-parsley, 1)]

b. * ALWAYS [a cat(Rodney)][eat(Rodney, my-parsley, 1)]

Assuming the constraint against vacuous quantification (i.e. that if there is an operator in an expression, there must be a variable in the restrictor clause for the operator to bind), (6b) is ill-formed because there is no variable in the restrictor clause ([a cat(Rodney)]) for the ALWAYS operator to bind. (6a), on the other hand, satisfies the constraint and is well-formed.

As for the fact that individual-level predicates resist modification by a temporal modifier, Kratzer claims that this is likewise captured by the fact that individual-level predicates do not contain an Event variable: it is the presence of this variable in stage-level predicates that allows such modification (the event itself gets modified).

A further semantic difference between stage- and individual-level predicates is that stage-level predicates admit an existential (weak) reading of a bare plural subject, while with individuallevel predicates the subject can have only a generic interpretation, as in (7a-b).

\footnotetext{
${ }^{4}$ The interesting issue of how predicates can be coerced into having a temporary or permanent meaning, contrary to their natural tendency, will not be taken up here. See Fernald (2000) for discussion.
} 
(7) a. Cats are in the kitchen. (existential ok)

b. Cats are mammals. (generic only)

Kratzer follows Diesing $(1988,1992)$ in accounting for this contrast in terms of the syntactic position of the Event argument. Namely, the Event argument is in SpecIP, and the subject of a stage-level predicate is generated lower in the structure, i.e. in SpecVP. Since the Existential Operator, $\exists$, is taken to be projected at the VP boundary and the Generic Operator, Gen, at the IP boundary, only elements within VP can receive an existential reading. Elements outside of VP, i.e. in IP, must be interpreted in the scope of the Generic operator.

These differences between stage- and individual-level predicates are semantic in nature and therefore call for a semantic-based account, which is what Kratzer provides. However, there are other contrasts that suggest a syntactic distinction between these two types of predicates. In particular, the unacceptability of individual-level predicates in perception verb complements is syntactic, not semantic in nature (i.e. (8b) is ungrammatical, not semantically ill-formed).

(8) a. I saw Rodney in the kitchen.

b. * I saw Rodney a cat.

A similar contrast is found in the coda of existential constructions.

(9) a. There are doctors in the corridor.

b. * There are doctors women.

What is the syntax of these constructions such that they allow only stage-level predicates to occur in them? Felser (1999) argues that perception verb complements (henceforth PVCs) contain AspP as their highest projection. Felser shows that the reduced clausal constituent under a perception verb involves more structure than a VP (it can host expletive subjects, as in (10a)) but less than a TP (it cannot be tensed, as in (10b)). ${ }^{5}$

(10) a. I wouldn't like to see [there be so many mistakes]

b. * I saw John draws/to draw a circle

Rather, she argues that the relevant level of projection is the functional projection between VP and TP, namely AspP (Travis, 1992). We might add that the head of this projection may be specified either as [+perf] or as [-perf] to capture the difference between (11a) and (11b), respectively. $^{6}$ (11a) denotes a closed eventuality (hence perfective), while (11b) denotes an ongoing (not closed) eventuality (hence imperfective).
a. I saw John draw a circle.
b. I saw John drawing a circle.

\footnotetext{
${ }^{5}$ The embedded clause under a perception verb can be infinitive if the main clause is passive: John was seen to draw a circle. I won't deal with these constructions here.

${ }^{6}$ Felser uses [ \pm progressive] as the feature of the Asp head. However, since we will apply the same structure to non-verbal predicates, which are not progressive, the [ \pm perfective] feature seems more appropriate, at least to the constructions under consideration here. I believe this is not more than a notational change.
} 
Since (im)perfectivity is what gets expressed by grammatical Aspect, and since the PVCs in (11a) and (11b) express perfectivity and imperfectivity, respectively, these predicates project an AspP.

(As a side note, Felser brings another argument for projecting AspP in PVCs: it is that PVCs can host eventive but not stative verbal predicates, and she associates only eventive (not stative) predicates with the projection of an Event argument. Furthermore, Felser places the Event argument in SpecAspP. Thus, sentences like (12b) are ruled out because they do not project an Event argument, and hence cannot occur with AspP:
a. I saw John draw a circle.
b. * I saw the book lie on the table?

While I do not adopt the view that only eventive predicates project an Event argument, the asymmetry between eventive and stative verbs in this environment is notable and must be accounted for. If there is an association between eventive verbs and Aspect that stative verbs do not share, the asymmetry in (12) is expected. Furthermore, an eventive/stative asymmetry arises in existential codas, another environment in which only stage-level predicates can occur: see below.)

We adopt Felser's view that PVCs involve AspP as the highest functional projection, and a nonverbal PVC, such as (8a) above has the structure in (13).

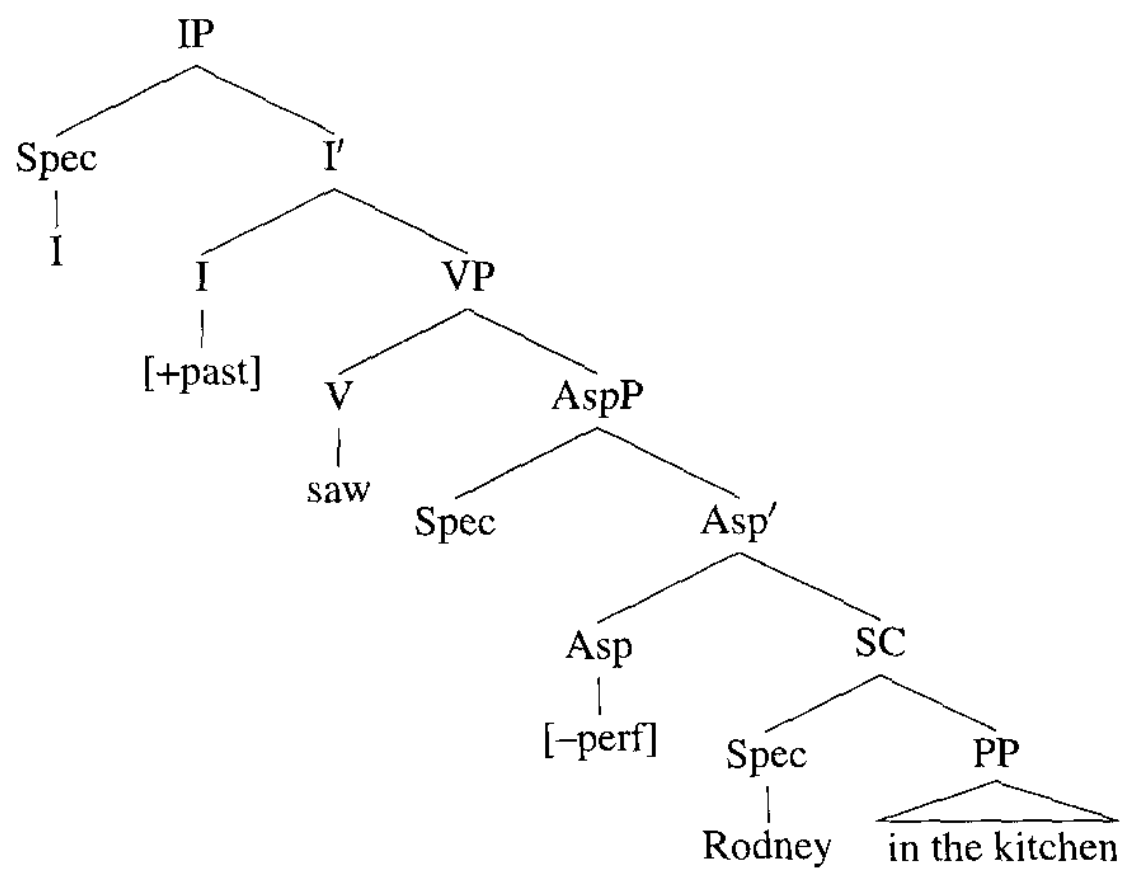

A sentence like ( $8 \mathrm{~b})$ is ruled out because individual-level predicates do not project AspP, so the ungrammaticality of $(8 \mathrm{~b})$ results from a selectional problem: individual-level predicates are non-aspectual and so are incompatible with AspP, yet AspP must be projected in a perception verb complement. The head of AspP in (13) is indicated as [-perf] (i.e. imperfective) rather than $[ \pm$ perf] as in the verbal PVC above because the predicate in (13)/(8a) does not denote a closed or completed eventuality. Instead, it is compatible with a continuation clause such as ... and he's

\footnotetext{
${ }^{7}$ Stative verbs may occur in progressive form in this environment (e.g. I saw the book lying on the table). However, these cases can be shown to involve a reduced relative clause, rather than a true perception verb complement structure. See Felser (1999) for discussion.
} 
still there. An imperfective verbal PVC such as (11b) likewise can be continued with ... and he's still drawing it, but a perfective PVC such as (11a) cannot be continued so: *I saw John draw a circle, and he's still drawing it. ${ }^{8}$

As for the exclusion of individual-level predicates in existential codas (cf. (9)), I will speculate that this can be argued to follow from the same restriction on predicates in PVCs. Namely, existential codas contain AspP. Notably, when the coda contains a verbal clause the verb must be eventive and must appear in progressive aspect.

(14) a. There are children playing in the yard.

b. ?* There are children knowing that song.

a. * There are children play in the yard.

b. * There are children know that song.

The contrast between (14a) and (14b) seems to suggest that existential codas, like PVCs contain AspP as the highest projection (if there is a connection between eventive predicates and Aspect, as suggested above). The ungrammaticality of (15a-b) can be accounted for by limiting the feature of $\mathrm{Asp}^{0}$ to [-perf]. That the head of AspP in an existential must be [-perf] receives some support from Giorgi and Pianesi's (1996) claim that English bare verbs are inherently perfective. As perfective predicates, they cannot be predicated of a "here and now" event. But according to Guéron (1995) existential there is a pronoun that denotes a time and place, i.e. it anchors the expression to the here and now. Thus, if existentials denote a here and now situation, then they should be incompatible with a perfective predicate, thus ruling out bare verbal predicates. ${ }^{9}$

\section{Further Evidence that S-level Predicates Contain AspP}

In addition to (certain) English embedded clauses, there is some evidence from other languages that stage-level predicates (or at least predicates that denote a more or less temporary property) should be associated with the projection of AspP. The languages I will discuss here are Russian, Spanish and Portuguese.

\subsection{Russian}

In Russian past tense predicative constructions, the nominal or adjectival predicate may bear either Nominative or Instrumental case. ${ }^{10}$ But the difference in case marking corresponds to a difference in meaning between the two predicates. A Nominative predicate has a permanent or inherent meaning, while an Instrumental predicate has a more temporary meaning, as shown in (16-17) (from Pereltsvaig (1999); see also Bailyn and Rubin (1991); Déchaine (1993)).

a. Oleg byl durakom.

Oleg-Nom was fool-Instr

'Oleg was a fool (sometimes he'd behave like a fool)'

\footnotetext{
${ }^{8}$ The perfective/imperfective contrast can be seen more clearly with the predicate drown. Compare: I saw Bill drowning, but I rescued him vs. *I saw Bill drown, but I rescued him. See Felser (1999) for discussion.

${ }^{9}$ I thank Nina Hyams for this suggestion and for discussion on this point.

${ }^{10}$ Russian predicatives in present tense always contain a null copula (never an overt one), and the predicate always bears Nominative case. I will not discuss present tense constructions here; but see Kondrashova (1996) for discussion.
} 
b. Oleg byl durak.

Oleg-Nom was fool-Nom

'Oleg was a fool (by nature, he was a foolish person)'
a. Pjatno bylo krasnym.
spot-Nom was red-Instr
'The spot was red (and then it changed color)'
b. Pjatno bylo krasnoe.
spot-Nom was red-Nom
'The spot was red (as long as there was a spot, it was red)'

Matushansky (2000) argues that Instrumental case is checked in SpecAspP, and therefore that predicates marked with Instrumental case project AspP. Her claim is twofold: one part involves evidence for an extra projection in Instrumental predicatives that is absent in Nominative predicatives, and the second part involves evidence that the extra projection in Instrumentals is Aspect. Let us look at the two claims individually.

Her evidence for the claim that Instrumental predicates involve an extra functional projection comes from extraction asymmetries between Nominative and Instrumental predicatives: in cases of Wh-extraction, scrambling and extraction from embedded clauses, extraction of the predicate is possible only when the predicate bears Instrumental case. An example of this asymmetry in scrambling is given below.
a. Velikim poètom byl Pushkin.
great poet-Instr was Pushkin
'Pushkin was a great poet.'
b. * Velikij poèt byl Pushkin.
great poet-Nom was Pushkin

Thus, she argues, the structure of clauses containing Instrumental predicates must be such that there is a position through which the predicate can move as it raises in the structure (cf. (18a)). This position must be absent in clauses containing Nominative predicates, since these predicates are not able to raise (cf. (18b)).

Matushansky's reason for invoking AspP in particular as the locus of Instrumental case checking (and the position through which the predicate may move) has to do with a more general association between Instrumental case and (im)perfectivity. In the above examples, the past tense copula byl 'was' is not marked for aspect. It may, however, occur in a form that bears an explicit morphological affix indicating (perfective or imperfective) Aspect. In this case the predicate must bear Instrumental case; Nominative is ungrammatical.

(19) Ja pobyla/byvala zavedujuščeh/*zavedujuščaja.

I was-perf/impf manager-Instr $/ *$ Nom

'I was/have been a manager'

This datum illustrates the connection between Instrumental case and Aspect: when the copula is explicitly marked for Aspect, the predicate can only have Instrumental case. Following Matushansky, this connection between Instrumental and Aspect should extend to those clauses where the copula does not bear any explicit aspectual morphology. That is, in past tense main 
clause predicatives such as (16a), if the predicate is marked with Instrumental case AspP is projected in the clause.

It is true that the semantic distinction found in Russian between Nominative and Instrumental predicates is not exactly the stage/individual distinction. At least, it is not the same distinction that is drawn in English (since, according to Carlson (1977), all nominal predicates are individual-level). Nevertheless there is a semantic difference between the predicates in the (a) and (b) examples in (16-17), and this semantic difference, namely that the one sort of predicate denotes an atemporal property and the other sort denotes a temporal property, is quite similar in nature to the difference between individual-level (atemporal) and stage-level (temporal) predicates. What I am suggesting here is that both distinctions should be accounted for in terms of the presence vs. absence of AspP in the syntax.

\subsection{Spanish and Portuguese}

In Spanish and Portuguese there are two copulas that both translate in English as be: ser and estar. The general distribution of these copulas is that ser occurs with individual-level predicates, and estar occurs with stage-level predicates, as in (20) from Spanish (see e.g. Sera, 1992; Luján, 1981; Bull, 1965; Roldan, 1974).
a. Juan es/*esta un hombre/grande.
John is-ser/*estar a $\mathrm{man} / \mathrm{big}$
'John is a man/big'
b. Juan esta/*es en la casa/cansado.
John is-estar/*ser in the house/tired
'John is in the house/tired'

Like their English counterparts, Spanish perception verb complements are restricted to stagelevel predicates. ${ }^{11}$ If the above analysis of PVCs for English is correct, then the following datum suggests that estar-predicates, but not ser-predicates project AspP.

(21) $\mathrm{Vi}$ a Juan en la casa/cansado/*profesor.

I saw A John in the home/tired/*teacher

'I saw John at home/tired/*a teacher'

Consistent with the idea that estar predicatives contain AspP but ser predicatives don't, Schmitt (1992) has argued independently that estar is an aspectual copula but ser is non-aspectual. That is, a predicate that occurs with estar carries temporal meaning: it relates to the temporal structure or constituency of an eventuality. As Schmitt argues, it denotes a result state. A predicate that occurs with ser is atemporal. A clear example of this difference can be seen in (22). ${ }^{12}$
a. Maria é quase bonita.
Maria is almost pretty
'Maria is sort of pretty'

\footnotetext{
${ }^{11}$ It is not clear whether this is the case in Portuguese, i.e. individual-level predicates are permitted in this context according to the judgment of one speaker of Brazilian Portuguese. At present I do not have an account of this fact.

${ }^{12}$ See also Luján (1981) for a similar argument that the serlestar distinction is an aspectual one.
} 
b. Maria está quase bonita.

Maria is almost pretty

'Maria is not pretty yet'

(Portuguese; from (Schmitt, 1992, p. 422))

In (22b), the adverb quase 'almost' modifies an event of becoming pretty, while in (22a), the adverb quase modifies the adjective itself. Since grammatical Aspect is something that relates to events, the structure for (22b) contains AspP, while the structure for (22a) does not.

\subsection{Summary}

Thus far I have made the argument that stage-level (or otherwise temporal) predicates project AspP, but individual-level (or otherwise atemporal) predicates do not. The evidence for this syntactic relationship came from English perception verb constructions and existential codas (although the case made from existentials was admittedly weaker), Russian past tense main clause predicatives and Spanish and Portuguese present tense predicatives. English PVCs were argued by Felser to contain AspP as the highest functional projection, and only stage-Jevel predicates are admitted in this environment. Russian past tense predicatives with Instrumental case on the predicate have a temporal interpretation and are argued by Matushansky to contain an AspP. (Past tense predicatives with Nominative case, in contrast, are non-aspectual: they have an atemporal meaning and do not project AspP.)

The alternation between stage- and individual-level predicatives in Spanish and Portuguese is an alternation in the lexical form of the copula: stage-level predicates occur with estar, while individual-level predicates occur with ser. The evidence for associating estar-predicates with AspP is much the same as in adult English: stage-level predicates have a temporal meaning and relate to the internal temporal structure of an eventuality, and thus encode Aspect. Individuallevel predicates are atemporal and therefore don't encode Aspect. The main difference in this respect between Spanish or Portuguese and English is that Spanish and Portuguese indicate the aspectual difference in terms of the lexical form of the copula, whereas English does not. In the next section, we will see that child English, like Spanish and Portuguese, displays a difference between stage - and individual-level predicatives in form (overtness vs. omission ) of the copula. It will then be argued that the Aspect-based analysis of the stage-/individual distinction allows us to account for the pattern of copula omission we find in child English.

\section{Child English}

Many of the facts discussed above for Russian, Spanish and Portuguese are well-known and widely discussed in the literature. Previously unknown, however, is the fact that child standard English displays a similar asymmetry between stage- and individual-level predicates in main clause predicatives. Like Spanish and Portuguese, the asymmetry appears as a difference in the form of the copula: in child English, we find a null/overt alternation in stage- vs. individual-level predicatives.

The data presented here come from the spontaneous speech utterances of four English-speaking children, taken from the CHILDES database (MacWhinney and Snow, 1985). In Table 1 I give the ages and average MLU (Mean Length of Utterance) of the children whose data are discussed here. ${ }^{13}$ The final column ( $\mathrm{Be}$ Contexts) lists the number of utterances in the relevant files that

\footnotetext{
${ }^{13}$ Mean Length of Utterance is the average number of morphemes per utterance, measured over the first 100 utterances in a file (Brown, 1973).
} 
either contained an overt copula or lacked a copula (but would require an overt copula in adult English).

Table 1: Children's Ages, MLU and Number of Predicatives

\begin{tabular}{|l|c|c|c|}
\hline Child (source) & Age Range & Avg. MLU & Be Contexts \\
\hline Nina (Suppes, 1973) & $2 ; 0-2 ; 2$ & 2.98 & 471 \\
Peter (Bloom, 1970) & $2 ; 0-2 ; 3$ & 2.84 & 785 \\
Naomi (Sachs, 1983) & $2 ; 0-2 ; 7$ & 3.09 & 555 \\
Adam (Brown, 1973) & $2 ; 7-3 ; 4$ & 3.38 & 792 \\
\hline
\end{tabular}

All four of the children in this study are at a stage of development in which they omit functional elements in some, but not all of their utterances. For example, they sometimes omit determiners, verbal inflectional morphology and auxiliary verbs in addition to the copula. Nevertheless, when these functional elements are used they are virtually error-free, and the copula is (correctly) inflected (e.g. is, am, etc., not be) $99.25 \%$ of the time. The files were chosen on the basis of the children's production of predicatives and of the copula: the earliest file selected for each child was the earliest at which the child used all types of predicatives, and the last file selected was the last one in which the child's rate of omitted be was significantly different in locative and nominal predicatives. The reason for using this criterion for choosing the last file for inclusion in the analysis will become clear when we look at children's asymmetric rates of omission of the copula.

First, let us examine children's omission of the copula in nominal and locative predicatives; we will return to adjectival predicatives in section 6 .

As shown in Table 2, children showed a strong tendency to use an overt (inflected) copula in nominal predicatives but to omit the copula in locative predicatives. ${ }^{14}$

Table 2: Average Rate of Overt Be in Children's Predicatives

\begin{tabular}{|l|ll|lc|}
\hline Child & \multicolumn{2}{|c|}{ Nominal Pred. } & Locative Pred. \\
\hline Nina & $74.1 \%$ & $(143)$ & $14 \%$ & $(115)$ \\
Peter & $81.2 \%$ & $(401)$ & $26.7 \%$ & $(90)$ \\
Naomi & $89.7 \%$ & $(102)$ & $38.1 \%$ & $(31)$ \\
Adam & $44.4 \%$ & $(303)$ & $4.9 \%$ & $(26)$ \\
\hline avg. & $\mathbf{7 2 . 4 \%}$ & & $\mathbf{2 0 . 9} \%$ \\
\hline
\end{tabular}

Adam's rates of overt be are noticeably lower than those of the other children, but his rates are lower in both categories. That is, he shows the same trend as the other children, but his rates of an overt copula are depressed overall. For comparison, the average rates of overt be excluding Adam's data are $81.7 \%$ for nominal predicatives and $26.3 \%$ for locative predicatives. Some examples of children's nominal and locative predicatives are given in (23) and (24) (the child's age at the time of utterance is given in years;months(.days)).

\footnotetext{
${ }^{14}$ In the table, the numbers in parentheses to the right of the percentages indicate the total number $(\mathrm{N})$ of copular utterances of each type. That is, Nina produced 143 nominal predicatives, $74.1 \%$ of which contained an overt copula.
} 
(23) a. I'm big boy. (Adam 2;7)

b. he's a dog. (Nina 2;0.24)

c. Patsy's a girl. (Peter 2;1.22)

d. she's a crocodile. (Naomi 2;3)

(24) a. my pen down there. (Peter 2;0.10)

b. I in the kitchen. (Nina $2 ; 1.15$ )

c. Eric at Cathy house. (Naomi $2 ; 4.30$ )

d. he way up dere [there]. (Adam 3;0.10)

It is interesting to note that the nominal predicates children use denote exclusively permanent properties (often an object's name or label), and their locative predicates denote exclusively temporary locations. Thus, while there may be predicates that do not possess the canonical properties of stage- or individual-level predicates (NP predicates that denote temporary properties, e.g. fugitive, and locative predicates that denote permanent locations, e.g. Paris is in France), children do not produce such predicates at this stage of development. The question of how these non-canonical predicates are analyzed in child English is an important one. Acknowledging that the correct analysis of these predicates in adult English is still not completely settled, it is an issue that I plan to pursue in future experimental work.

\section{Analysis}

To recapitulate briefly, the structure proposed for individual-level predicatives is that in (25a), and the structure proposed for stage-level predicatives is that in (25b).

a.

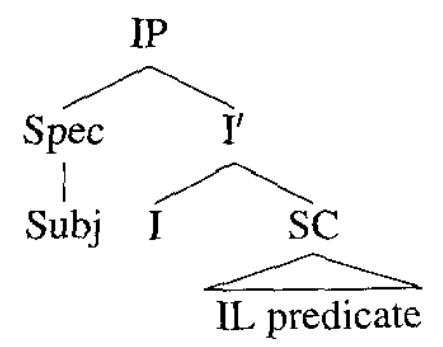

b.

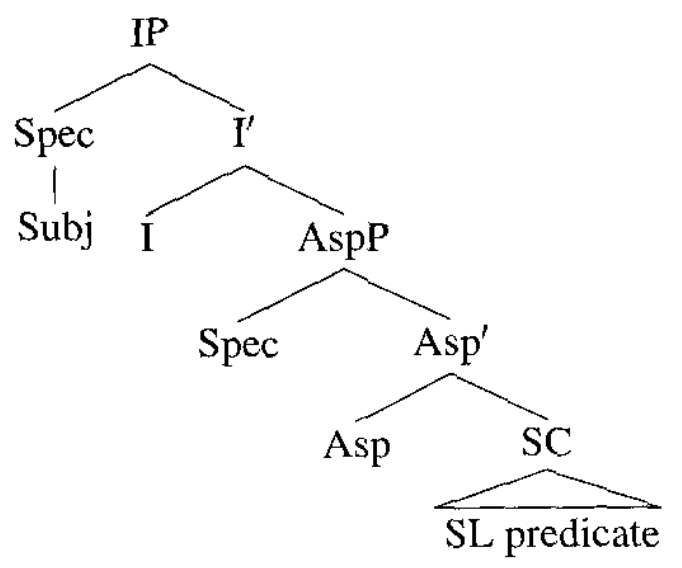

We saw in the previous section that children acquiring English omit the copula when AspP is projected in the structure, and they produce an overt (and inflected) copula when AspP is not projected. This result may seem surprising, a priori, since children appear to be adding something to the string when there is less structure, but leaving something out of the string 
when there is more structure. So we should ask how it is that the syntactic asymmetry between stage- and individual-level predicates, argued for in sections 2 and 3, helps us account for the asymmetry in the overtness of the copula in child English. Put another way, why does AspP "block" the occurrence of an overt copula? To see how it does so, let us turn to the temporal anchoring of main clauses.

Let us assume that all main clauses must be anchored to the discourse in order to receive a temporal interpretation, and this is done via an abstract Tense Operator $\left(\mathrm{T}_{O P}\right)$ located in the C-domain. ${ }^{15}$ Let us further suppose that all indicative main clauses must be anchored by this operator. Temporal anchoring obtains when $\mathrm{T}_{\mathrm{OP}}$ binds a functional head in the matrix clause that is associated with the temporal structure of the clause. The functional heads associated with temporal structure are Infl and Asp. ${ }^{16}$ The particular head that must be bound is determined by the particular grammar and may vary across languages, in a way to be made explicit directly.

Let us define temporal anchoring in the following way.

\section{Definition}

Temporal Anchoring:

i. A main clause is temporally anchored if the Tense Operator $\left(\mathrm{T}_{\mathrm{OP}}\right)$ binds an appropriate functional head in the structure, where an appropriate head is either Infl or Asp.

ii. In some languages $\mathrm{T}_{O P}$ binds only Inff; in other languages it binds Asp (when projected).

Further, let us define grammatical finiteness in terms of temporal anchoring, so that a main clause is finite when $\mathrm{T}_{O P}$ binds Infl, but not otherwise. In other words, Infl is the sort of head that, if bound by $T_{O P}$, results in morphosyntactic finiteness (provided the particular language contains morphology to express finiteness). Asp is not the sort of head that bears finiteness features, so a clause in which $T_{O P}$ binds Asp is not finite (nor is it infinitive: Asp ${ }^{0}$ simply does not relate to grammatical finiteness).

In adult English, all indicative main clauses are finite (the main verb or auxiliary element, if present, carries tense or agreement features, which may or may not be realized overtly). Therefore, in adult English $\mathrm{T}_{O P}$ always binds Infl, whether or not AspP is projected in the structure.

Thus, the structures of individual- and stage-level predicatives in adult English are then those in (27a) and (27b), respectively.

a.

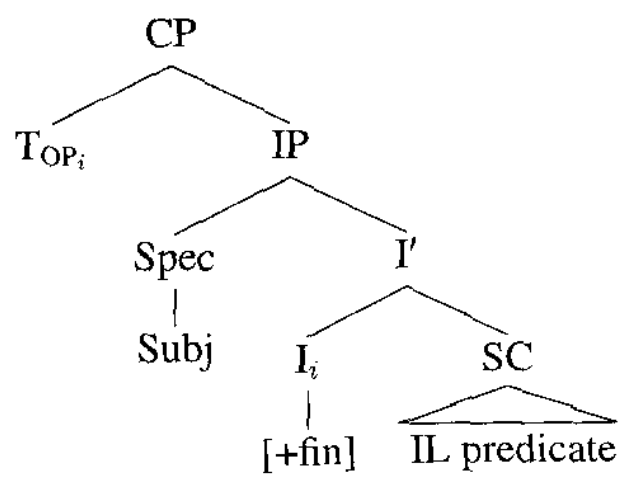

\footnotetext{
${ }^{15}$ Enç (1987) and Guéron and Hoekstra (1995) have both proposed such an operator; for Enç the operator is in the head, $\mathrm{C}^{0}$, while for Guéron and Hoekstra it is in SpecCP. I remain neutral on the issue of its precise location within the CP projection.

${ }^{16}$ I do not distinguish between the heads Infl and Tns.
} 
b.

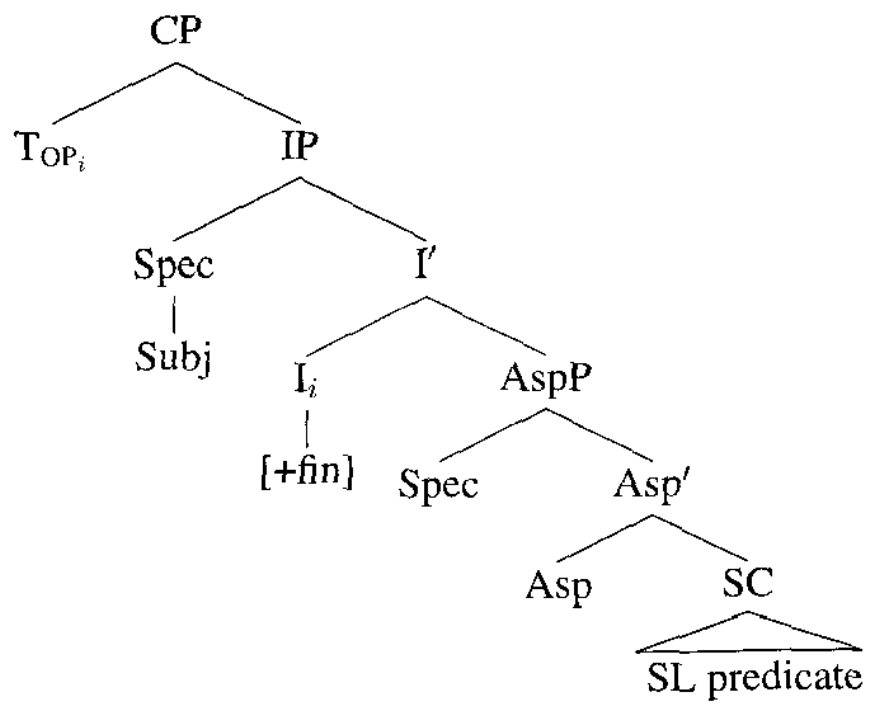

But in grammars in which the temporal anchoring requirement is satisfied through the binding of $\mathrm{Asp}^{0}$ (when projected), not all main clauses will be finite. In particular, stage-level predicatives involve a bound Asp instead of a bound Inf, and these expressions are not finite. I argue here that child English is a grammar in which $A \mathrm{sp}^{0}$ is bound by $\mathrm{T}_{O P}$ when Asp is projected. Thus, the structures for individual- and stage-level predicatives in child English are given in (28a-b).

a.

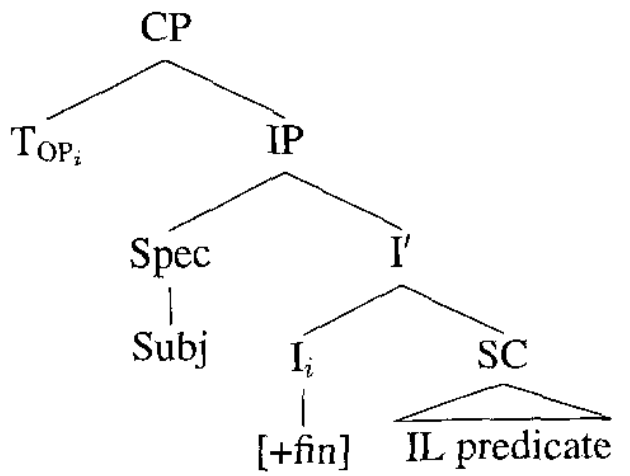

b.

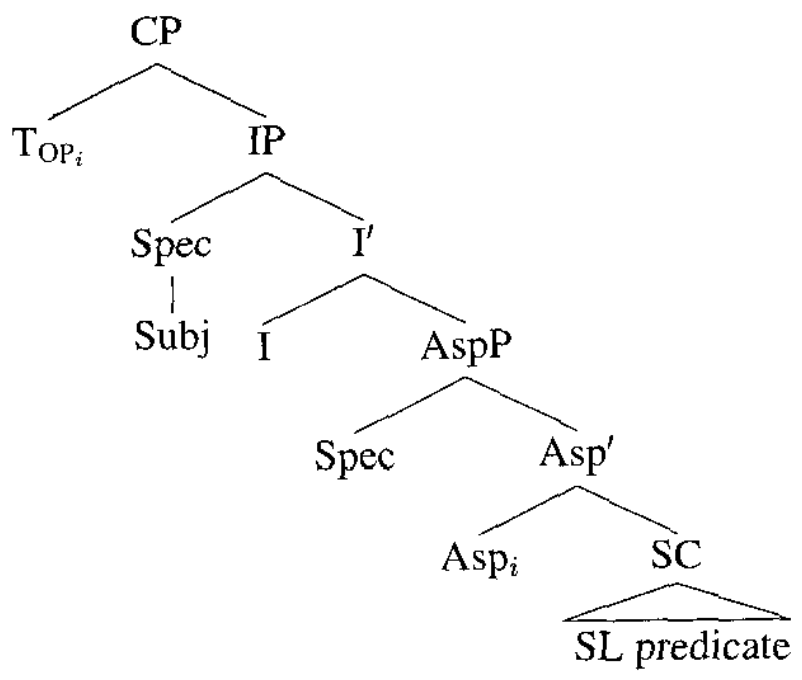

I should point out here that Infl in (28b) does not have a [-fin] feature, rather it is just empty. In spite of its being empty, we still want to project IP (as opposed to projecting only as far as AspP; e.g. one might propose this if one believes children's clause structures are reduced-see Rizzi (1994)). IP must be projected even when Infl is not finite, because some of children's nullcopula predicatives contain Nominative subjects (e.g. I in the kitchen). In such cases we would 
need to have a position for the subject to move to which is high enough to get Nominative case. I assume that the canonical subject position is the appropriate position. (See also arguments in Schütze (1997) for the view that IP must be projected in children's main clauses.)

The difference between child and adult English, then, amounts to a difference in the way in which the temporal anchoring requirement is satisfied. In adult English it is satisfied through the binding of Infl, regardless of whether Asp is projected in the structure or not. In child English it is satisfied through the binding of Infl only if Asp is not projected (i.e. in individual-level predicatives) (otherwise, the requirement is satisfied through the binding of Asp). Recall the claim made above that main clauses in which Infl is bound by $T_{O P}$ are finite, while clauses in which Infl is not bound (i.e. those in which Asp is bound) are non-finite. In predicative constructions, finiteness is expressed via an inflected copula, and non-finiteness is indicated by the absence of an inflected copula. By defining finiteness in this way, we capture the association in child English between the projection of Asp and a null copula, and between the lack of Asp and an overt, inflected copula.

\section{Adjectival Predicatives}

Although the asymmetry in copula omission between nominal and locative predicatives is robust and clear, it is somewhat less robust among individual-level and stage-level adjectival predicatives. Nevertheless, three of the four children do show an asymmetry in the expected direction (a higher rate of overt be with individual- than stage-level adjectival predicates), and I will argue that adjectives introduce independent difficulties.

In Table 3 I give the children's average rate of overt be in adjectival predicatives.

Table 3: Average Rate of Overt $\mathrm{Be}$ in Children's Adjectival Predicatives

\begin{tabular}{|l|ll|ll|}
\hline Child & \multicolumn{2}{|l|}{ IL Adjectives } & \multicolumn{2}{|c|}{ SL Adjectives } \\
\hline Nina & $75.3 \%$ & $(24)$ & $49.5 \%$ & $(38)$ \\
Peter & $60 \%$ & $(29)$ & $39.8 \%$ & $(87)$ \\
Naomi & $93.5 \%$ & $(29)$ & $52 \%$ & $(64)$ \\
Adam & $44.4 \%$ & $(35)$ & $43.3 \%$ & $(80)$ \\
\hline Avg. & $\mathbf{6 8 . 3 \%}$ & & $\mathbf{4 6 . 2 \%}$ & \\
\hline
\end{tabular}

Some examples of children's adjectival predicatives are given in (29).
a. this empty. (Peter 2;3.3)
b. this is orange. (Peter 2;3.3)
c. her thirsty. (Nina 2;2.6)
d. Mommy's little. (Nina 2;1.22)
e. you warm enough. (Naomi $2 ; 5$ )
f. and this is yellow. (Naomi 2;5)

Once again, Adam's utterances pattern somewhat differently from those of the other children in that he does not show a difference in his rate of overt $b e$ between stage- and individual-level adjectives. In fact, Adam's rate of overt be in adjectival predicatives is the same as his rate of overt 
be in nominal predicatives, suggesting that if there is a syntactic reason behind children's omitted copulas, Adam's grammar assigns the same (in relevant respects) structure to both adjectival and nominal predicatives, but a different one to locatives. According to the present analysis this would entail that Adam's adjectival predicates uniformly lack AspP. However, given Adam's overall low rate of overt be, I hesitate to take a strong position on this particular issue. For comparison, the average rates of overt be in adjectival predicatives excluding Adam are $76.2 \%$ and $47.1 \%$. The reasons for Adam's different rate of omitting the copula is not totally clear, but it is possible that Adam was exposed somewhat to African American English, in which null copula main clauses are grammatical, and perhaps this had an effect on his tendency to omit the copula.

The overall weaker distinction between stage- and individual-level predicates in terms of children's copula omission may seem surprising if children indeed have grammatical knowledge of the stage/individual distinction. However, there are a number of factors concerning adjectives that suggest that adjectives are not straightforwardly classified as stage- or individual-level, and therefore that they might not pattern exactly like nominal and locative predicates.

There are certain adjectives that behave in some respects like stage-level predicates and in other respects like individual-level predicates. For example, as discussed by Jäger (1999), available denotes a temporary property, it can be modified by temporal modifiers (e.g. John is available on Tuesdays), its bare plural subject can get a weak reading (e.g. Firemen are available: existential $\mathrm{OK}$ ) and it can occur in an existential coda (There are firemen available), but it cannot occur in a PVC $(* I$ saw John available $)$. There are also a number of adjectives that are individual-level in the unmarked case (e.g. John is mean), but which can be easily coerced into a stage-level meaning in different syntactic contexts. For example, these adjectives occur in the "active $b e$ " context (John is being mean) and in Stowell's (Stowell, 1991) "mental property" contexts (John was mean to hit Bill/It was mean of John to hit Bill) (please see Fernald (2000) for a discussion of coercion).

Moreover, since adjectives constitute a single lexical category, children cannot classify adjectives as stage- or individual-level simply on the basis of their lexical category, as they might, for example, with NP and PP predicates. Rather, the stage- or individual-levelhood of each adjective must be learned on an item-by-item basis. For this reason, and because of the existence of discrepancies between the temporary/permanent meaning of an adjective and its behavior in the stage/individual tests, I conclude that children's somewhat weaker stage/individual distinction in terms of their omission of the copula with adjectival predicates does not constitute counterevidence to the general pattern. Therefore, I maintain the generalization that children tend to produce an overt copula with individual-level predicates, and they tend to omit the copula with stage-level predicates.

\section{Hebrew}

According to the present analysis, the omission of the copula in child English predicatives results from the fact that $\mathrm{T}_{O P}$ binds $\mathrm{Asp}^{0}$ to satisfy the temporal anchoring. If this option is made available by UG and if child grammars are subject to the full range of UG principles that govern adult grammars (i.e. if this is not a property only of "pre-mature", or non-adult grammars), then we would predict that there are adult grammars that display the same pattern of copula omission in main clauses as we find in child English. Here I would like to suggest that adult Hebrew is such a language.

In Hebrew present tense predicatives the copula is not verbal, unlike its past and future tense counterpart (h.y.y) (Doron, 1983; Rapoport, 1987; Rothstein, 1987; Greenberg, 1994; Rothstein, 
1995, among others). Rather, it is the spellout of Agreement material in Infl (Rapoport, 1987). Also unlike the past and future tense verbal copula, the "pronominal" copula, or Pron ( $h u$ in masculine singular), is omitted in some predicatives but overt in others (the verbal copula in past and future tenses is obligatorily overt in all main clause predicatives).

Some examples are given in (30) (from Greenberg, 1994)).
a. ha-kli ha-ze $*(h u)$ patis
the-tool the-this $3 \mathrm{~m} . \mathrm{sg}$ hammer
"This tool is a hammer."
b. Dani (*hu) me'od 'ayef ha-yom
Dani $3 \mathrm{~m} . \mathrm{sg}$ very tired the-day
"Dani is very tired today."
c. ha-Samyim (hem) kxulim
the-sky 3m.pl blue
"The sky is blue."

The predicate in (30a) denotes an inherent, indeed, definitional property of the subject, and Pron must be overt. The predicate in $(30 \mathrm{~b})$ denotes a temporary, non-inherent property, and Pron must be null. In (30c), Pron is optionally overt, but its overtness/covertness corresponds to a difference in the meaning of the predicate. When Pron is overt the sentence means "The sky is blue (as opposed to some other color, e.g. red)"; when Pron is null the sentence means "The sky is blue (right now, as opposed to being overcast)".

Greenberg (1994) shows that in predicatives with an overt pronominal copula the predicate denotes an inherent or generic property (e.g. orvim *(hem) Sxorim 'Ravens are black'), while in predicatives with a null copula the predicate denotes a non-inherent or non-definitional property. Thus, Hebrew appears to divide predicates into temporal and atemporal properties along somewhat different lines than a language like adult English. For example, the predicate more 'teacher' could be temporal or atemporal in Hebrew, but it is only atemporal (individual-level) in English. Nevertheless, the syntactic result that temporal predicates project AspP and atemporal predicates do not project AspP is the same in both languages. Moreover, the morphological reflex of this asymmetry is the same in Hebrew as in child English: in Hebrew, predicates that denote non-inherent properties project AspP, and in these cases $A_{s p}{ }^{0}$ is bound by $T_{\mathrm{OP}}$, hence there is no overt copula. Predicates that denote inherent properties do not project AspP; in these cases the only head available for binding by $T_{O P}$ is Infl. When Infl is bound it is spelled out as the pronominal copula.

\section{Summary and Open Questions}

The main argument made in this paper is that the semantic contrast we know as the stagelevel/individual-level distinction corresponds to a syntactic (aspectual) difference between predicative structures. Stage-level and otherwise temporal predicates project AspP above the lexical Small Clause. Individual-level and otherwise atemporal predicates do not project AspP. Support for the association between stage-level predicates and AspP (and between individual-level predicates and the lack of AspP) was provided from English perception verb complements and existential codas (which admit only stage-level predicates and arguably contain AspP), Russian 
past tense predicatives (Instrumental case-marked predicates have a temporal meaning, and Instrumental is checked in SpecAspP) and Spanish and Portuguese main clause (present tense) predicatives (the ser/estar distinction was argued to be an aspectual one).

The analysis of the stage/individual contrast as a syntactic aspectual distinction provides a basis for accounting for the asymmetry in the overtness of the copula in child English. As shown in section 4, children acquiring English tend to omit the copula with stage-level predicates but use an overt, inflected copula with individual-level predicates, a pattern seen most clearly in nominal and locative predicatives. The formal requirement of temporal anchoring defined in section 5 allows us to capture this null-/overt-copula alternation. Stage-level predicates contain AspP, and in child English $\mathrm{Asp}^{0}$ can be bound by $\mathrm{T}_{\mathrm{OP}}$ to satisfy the temporal anchoring requirement. Main clauses containing these predicates are non-finite in child English (realized as a null copula) because Infl is not bound by $\mathrm{T}_{\mathrm{OP}}$, rather, it is Asp that is bound. Individual-level predicates, instead, lack AspP, so the only functional head available for binding by $T_{O P}$ is Infl. When Infl is bound, the clause is finite, and in (non-verbal) predicatives finiteness is spelled out as an inflected copula. Adult English, in contrast to child English, never allows Asp ${ }^{0}$ to satisfy the temporal anchoring requirement, and so in all main clauses in adult English, Infl is bound by $\mathrm{T}_{\mathrm{OP}}$, and the copula is overt and inflected.

\section{References}

Bailyn, John and Edward Rubin (1991): The Unification of Instrumental Case Assignment in Russian, in: A. Toribio and W. Harbert (eds.), Cornell University Working Papers in Linguistics, volume 9, 99-126.

Becker, Misha (to appear): English Has Two Copulas, submitted to Penn Working Papers in Linguistics.

Bloom, Lois (1970): Language Development: Form and Function in Emerging Grammars, MrT Press, Cambridge, MA.

Brown, Roger (1973): A First Language, Harvard University Press, Cambridge, MA.

Bull, W. (1965): Spanish for Teachers, Ronald Press, New York.

Carlson, Gregory (1977): Reference to Kinds in English, Ph.D. thesis, UMass Amherst.

Carlson, Gregory (1979): Generics and Atemporal When, Linguistics and Philosophy, 3 49-98.

Comrie, Bernard (1976): Aspect: An Introduction to the Study of Verbal Aspect and Related Problems, Cambridge University Press, Cambridge.

Davidson, Donald (1967): The Logical Form of Action Sentences, in: Essays on Actions and Events, 105-148, Oxford University Press, Oxford.

Déchaine, Rose-Marie (1993): Predicates Across Categories: Towards a Category-Neutral Syntax, Ph.d. dissertation, UMass Amherst.

Diesing, Molly (1988): Bare Plural Subjects and the Stage/Individual Contrast, in: Genericity in Natural Language: Proceedings of the 1988 Tubingen Conference, Tübingen.

- (1992): Indefinites, MIT Press, Cambridge, MA.

Doron, Edit (1983): Verbless Predicates in Hebrew, Ph.d. dissertation, University of Texas at Austin.

Enç, Mürvet (1987): Anchoring Conditions for Tense, Linguistic Inquiry, 18 633-658.

Felser, Claudia (1999): Verbal Complement Clauses: A Minimalist Study of Direct Perception Constructions, John Benjamins Publishing Co., Philadelphia.

Fernald, Theodore (2000): Predicates and Temporal Arguments, Oxford University Press, Oxford.

Giorgi, Alessandra and Fabio Pianesi (1996): Tense and Aspect: From Semantics to Morphosyntax, ms., University of Bergamo \& IRST.

Greenberg, Yael (1994): Hebrew Nominal Sentences and the Stage/Individual-Level Distinction, Master's thesis, Bar-Ilan University.

Guéron, Jacqueline (1995): On HAVE and BE, in: Proceedings of NELS 25, GLSA, Amherst, MA. 
Guéron, Jacqueline and Teun Hoekstra (1995): The Temporal Interpretation of Predication, in: Anna Cardinaletti and Maria-Teresa Guasti (eds.), Syntax and Semantics 28: Small Clauses, Academic Press.

Jäger, Gerhard (1999): Stage Levels, States, and the Semantics of the Copula, ms., Zentrum für Allgemeine Sprachwissenschaft, Berlin.

Kondrashova, Natalia (1996): The Russian Copula: A Unified Approach, in: Annual Workshop on Formal Approaches to Slavic Linguistics: the College Park Meeting 1994, Michigan Slavic Publications, Ann Arbor.

Kratzer, Angelika (1995): Stage-Level and Individual-Level Predicates, in: Gregory Carlson and Francis Pelletier (eds.), The Generic Book, 125-175, University of Chicago Press, Chicago.

Luján, Marta (1981): The Spanish Copulas as Aspectual Indicators, Lingua, 54 165-210.

MacWhinney, Brian and Catherine Snow (1985): The Child Language Data Exchange System, Journal of Child Language, 12 271-296.

Matushansky, Ora (2000): The Instrument of Inversion: Instrumental Case and Verb Raising in the Russian Copula, in: Roger Billerey and Brook Lillehaugen (eds.), Proceedings of WCCFL 19, Cascadilla Press, Somerville, MA.

Pereltsvaig, Asya (1999): Case, Interpretation and Clausal Structure: Issues in Russian Copular Constructions, dissertation prospectus, McGill University.

Rapoport, Tova (1987): Copular, Nominal and Small Clauses: A Study of Israeli Hebrew, Ph.D. thesis, MIT.

Rizzi, Luigi (1994): Some Notes on Linguistic Theory and Language Development: The Case of Root Infinitives, Language Acquisition, 3 371-395.

Roldan, M. (1974): Towards a Semantic Characterization of Ser and Estar, Hispania, 57 68-75.

Rothstein, Susan (1987): Three Forms of English Be, in: M. Browning, E. Czaykowski-Higgins and E. Ritter (eds.), MITWPL vol. 9, 225-237, MITWPL.

- (1995): Small Clauses and Copular Constructions, in: Anna Cardinaletti and Maria-Teresa Guasti (eds.), Syntax and Semantics 28: Small Clauses, Academic Press.

Sachs, J. (1983): Talking About the There and Then: The Emergence of Displaced Reference in Parent-Child Discourse, in: K. E. Nelson (ed.), Children's language, Lawrence Erlbaum, Hillsdale, NJ.

Schmitt, Cristina (1992): Ser and Estar: A Matter of Aspect, in: Proceedings of NELS 22, GLSA.

Schuitze, Carson (1997): Infl in Child and Adult Language: Agreement, Case and Licensing, Ph.D. thesis, MIT.

Sera, Maria (1992): To Be or To Be, Journal of Memory and Language, 31 408-427.

Stowell, Timothy (1981): Origins of Phrase Structure, Ph.D. thesis, MIT.

- (1991): Alignment of Arguments in Adjective Phrases, in: Syntax and Semantics 25: Perspectives on Phrase Structure, Academic Press.

Suppes, Patrick (1973): The Semantics of Children's Languages, American Psychologist, 88 103-114.

Travis, Lisa (1992): Inner Aspect and the Structure of VP, in: Proceedings of NELS 22. 